Gijs D. Vos

Jim van Os

Piet L. J. M. Leroy

Jan N. M. Schieveld

\section{Pets or meds: how to tackle misery in a paediatric intensive care unit}

Accepted: 17 May 2007

Published online: 19 June 2007

(C) Springer-Verlag 2007

Sir: Rates of mood disorder and delirium in patients admitted to an intensive care unit are high and associated with a poor prognosis, as evidenced by longer hospital stay, poorer functional and cognitive outcomes and higher mortality rates after discharge from hospital. Among the adult population, the incidence is particularly high in geriatric patients [1]. In paediatric patients, similarly high rates of psychiatric disorder, mainly mood disorder and delirium, are observed, with reported rates of $5-40 \%[2,3]$. Targeted pharmacological interventions may be used for primary and secondary prevention, but a common-sense population approach towards prevention in the form of extensive psychosocial interventions may be more productive, particularly in high-risk paediatric intensive care unit (PICU) settings [3-5]. Thus, parents' presence and comfort throughout the day (and night), familiar music, favourite toys, pictures, lighting schedules and sometimes even fragrances may be used productively in all admitted patients.

One of our patients, a 12-year-old girl, became less talkative, displayed a sad facial expression, and lost interest in the surrounding environment. She was known with spina bifida,
Arnold Chiari type II malformation, and central hypoventilation during sleep. She was hospitalized because she required non-invasive ventilation during the night, and for a plastic surgery procedure. As she clearly developed an adjustment disorder with depressed mood, an intensification of the routine psychosocial protocol was attempted - guided by the words of colleague David Mrazek: "During the prolonged hospitalization of young children, the single most important aspect of treatment is to ensure that the primary attachment figures are available..." [6] - by allowing her friend Orka to visit her daily (Fig. 1). Orka was the patient's assistance dog, permanently placed in her home to provide therapeutic benefits. After the change in the psychosocial protocol allowing for the canine company, the patient did very well during her stay on the PICU, became cheerful and started talking and making jokes again to the nurses and doctors, and did not need any further treatment. There were no complications due to Orka's visits; in particular, no infections arose.

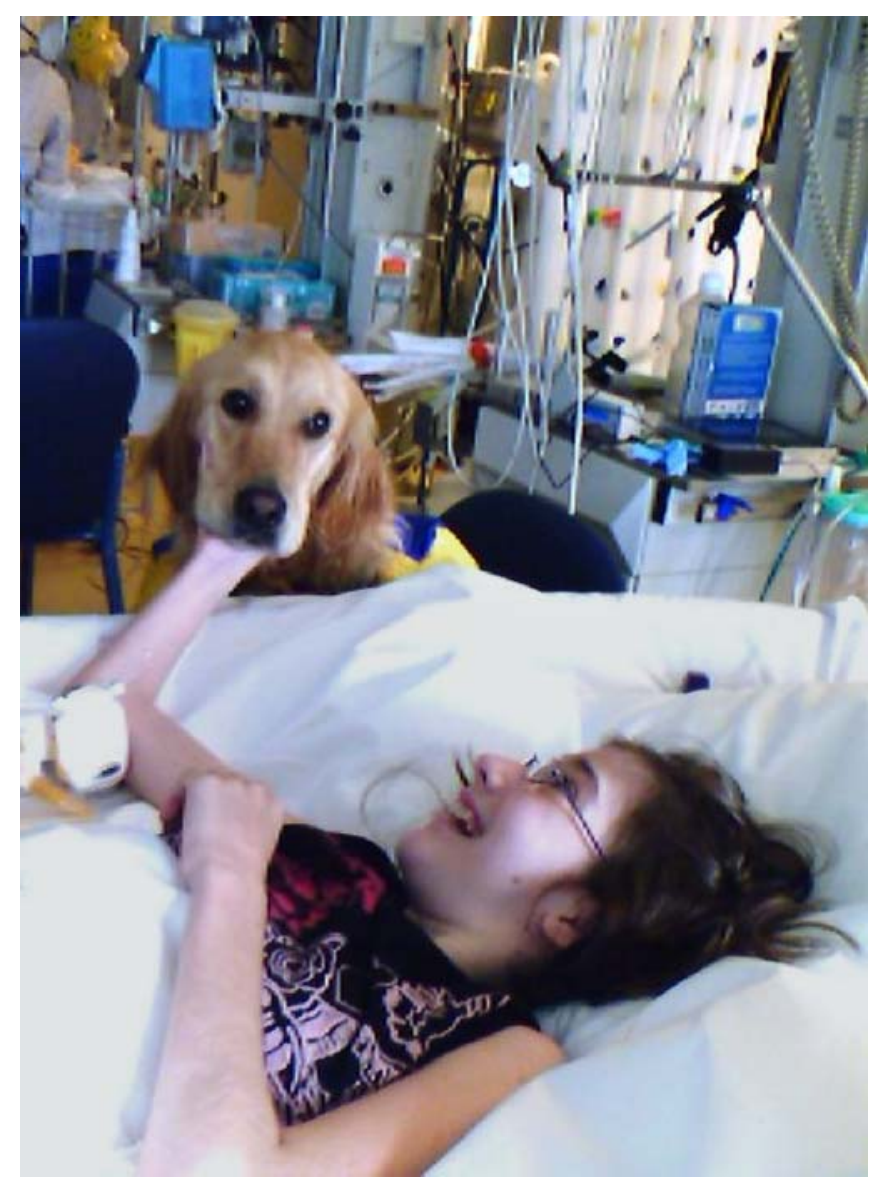

Fig. 1 Published with written permission of the patient and her parents. The patient gave written permission on behalf of Orka, who agreed with: 


\section{References}

1. Ely EW, Shintani A, Truman B, Speroff T, Gordon SM, Harrell FE Jr, Inouye SK, Bernard GR, Dittus RS (2004) Delirium as a predictor of mortality in mechanically ventilated patients in the intensive care unit. J Am Med Assoc 291:1753-1762

2. Mrazek DA (2002) Psychiatric aspects of somatic disease and disorders. In: Rutter M, Taylor E (eds) Child and adolescent psychiatry, 4th edn. Blackwell, Oxford, pp 810-827

3. Schieveld JNM, Leroy PLJM, van Os JJ, Nicolai J, Vos GD, Leentjens AFG (2007) Pediatric delirium in critical illness: phenomenology, clinical correlates and treatment response in 40 cases at the pediatric intensive care unit. Intensive Care Med DOI 10.1007/s00134-007-0637-8
4. Schieveld JNM, Leentjens AFG (2005) Delirium in severely ill young children in the pediatric intensive care unit (PICU). J Am Acad Child Adolesc Psychiatry 44:392-394

5. Inouye SK, Bogardus ST, Williams CS, Leo-Summers L, Agostinin JV (2003) The role of adherence on the effectiveness of non-pharmacologic interventions. Arch Intern Med 163:958-964

6. Mrazek DA (2002) Chronic pediatric illness and multiple hospitalizations. In: Lewis M (ed) Child and adolescent psychiatry, 3rd edition. Lippincott Williams \& Wilkins, Philadelphia, pp 1230-1238
G. D. Vos $(\varangle)$ • P. L. J. M. Leroy

University Hospital Maastricht, Division of Paediatric Intensive Care, Department of Paediatrics,

P.O. Box 5800, 6202 AZ Maastricht,

The Netherlands

e-mail: gvo@paed.azm.nl

J. van Os · J. N. M. Schieveld

University Hospital Maastricht, Division of Child and Adolescent Psychiatry,

Department of Psychiatry,

P.O. Box 5800, 6202 AZ Maastricht,

The Netherlands

J. van Os

Institute of Psychiatry, Division of

Psychological Medicine,

SE5 8AF London, UK 